\title{
INCUBATION STUDIES ON EXCHANGEABLE Zn FOR VARYING LEVELS OF ADDED Zn UNDER AEROBIC AND ANAEROBIC CONDITIONS IN GREY TERRACE SOILS, NON CALCARIOUS FLOODPLAIN SOILS AND CALCARIOUS FLOODPLAIN SOILS
}

\author{
K H Talukder ${ }^{1}$, I U Ahmed ${ }^{2}$, M S Islam ${ }^{3}$ M. Asaduzzaman ${ }^{4}$ and M D Hossain ${ }^{5}$
}

\begin{abstract}
Fractions studies were done to know how the zinc applied to different soils was distributed in to various fractions when the soils incubated under aerobic and anaerobic condition. The added zinc provided significant increase in exchangeable $\mathrm{Zn}$ both under aerobic and anaerobic conditions although anaerobic condition gave lower results than aerobic condition. The higher results were obtained at early stage of incubation and it gradually reduced as the incubation period proceeded to 90 days. These results showed all most similar trends for all the soils under study. In general, added zinc showed significantly higher results to the different fractions of soil Zn both under anaerobic and aerobic incubation with very few exceptions. The highest amount of added Zn (12 kg/ha) always produced greater results than the lower doses. Only exchangeable $\mathrm{Zn}$ was found higher in the 1st measurement at $15 \mathrm{DAI}$ then gradually decreased but in other cases, gradual increase in zinc fractions was seen as the incubation study proceed to longer duration provided with very few exceptions. In many cases, the exchangeable-Zn found higher only at 15 DAI but sharply reduced at 30 DAI. In general, the Gray Terrace Soil produced the highest results followed by Non Calcareous Gray Floodplain and the lowest results were observed in Dark Grey Floodplain \& Brown Floodplain Soil.
\end{abstract}

Keywords: Added Zn, Significant increase, Exchangeable Zn, Aerobic and Anaerobic Condition

\section{INTRODUCTION}

Iyengar et al. (1981) described the distribution and plant availability of zinc in different soil fractions. Total Zn (TZn) in 19 soils, which varied widely in chemical and physical properties was fractionated into water-soluble plus exchangeable (CA-Zn), specially adsorbed (AC-Zn), organically bound (PYRO-Zn), Mn-oxide bound (HAH-Zn), Al and Fe-oxide bound (AMOX-Zn), and residual (RES-Zn) forms. There was a wide variation in the magnitude of these fractions among soils. Most of the $\mathrm{Zn}$ on an average, was present in the AMOX-Zn (25\%) and RES-Zn (70\%) fractions. The CA-Zn, AC-Zn,

\footnotetext{
${ }^{1}$ Dean, Faculty of Agriculture, Biological Science, Biotechnology and Textile, Atish Dipankar University of Science and Technology, Bangladesh.

2 Former Professor ,Department of Soil, Water and Environment ,University of Dhaka and former President ,The Peoples' Republic of Bangladesh.

3 Former Director General, Bangladesh Agricultural Research Institute Joydebpur, Bangladesh.

4 Executive Director, Bangladesh Science Foundation, Dhaka, Bangladesh.

5 Lecturer, Department of Agribusiness, Atish Dipankar University of Science and Technology, Bangladesh.
} 
PYRO-Zn, and HAH-Zn fractions averaged 0.4, 3.3, 2.5 and 2.0\% of the total Zn, respectively. The CA-Zn in the 19 soils increased with a decrease in soil $\mathrm{pH}$, whereas the AC-Zn increased with an increase in soil $\mathrm{pH}$. The PYRO-Zn in the soils varied directly with organic $\mathrm{C}$ and soil $\mathrm{pH}, \mathrm{HAH}-\mathrm{Zn}$ increased with an increase in both soil $\mathrm{pH}$ and free $\mathrm{Mn}$, AMOX-Zn correlated more closely with free Al than with free Fe, and RES-Zn varied positively with soil clay. Prasad and Sakal (1988) studied the distribution of different chemical pools of $\mathrm{Zn}$ in 25 Calcareous soils on North Bihar and observed that the water soluble, exchangeable, complexed, organically bound, occluded and residual fractions constituted on an average about $0.03,0.5,1.9,1.3,1.6$ and $94.6 \%$ respectively of total Zn content of soil. Most of the $\mathrm{Zn}$ fractions were correlated negatively and significantly with $\mathrm{pH}$ and free $\mathrm{CaCO}_{3}$ and positively and significantly with organic carbon and clay content of the soil. In general, the $\mathrm{pH}, \mathrm{CEC}$, $\mathrm{CaCO}_{3}$, active $\mathrm{CaCO}_{3}$ and $\mathrm{HCO}_{3}$ showed negative correlations with different pools of $\mathrm{Zn}$ in soil, where as organic carbon, clay and $\mathrm{Fe}_{2} \mathrm{O}_{3}$ showed positive relationships. The significant and positive correlation among different pools of soil $\mathrm{Zn}$ point to the existence of dynamic equilibrium among the various forms of soil Zn. Prasad et al. (1980) observed that the transformation and availability of applied Zn in Calcareous soil treated with organic materials viz. sewage sludge, municipal wastes, poultry manure, pressumed. Most of zinc existed as residual zinc (41\% of total Zn). Shuman, (1985) observed that the influence of tillage on the distribution of $\mathrm{Mn}, \mathrm{Cu}, \mathrm{Fe}$ and $\mathrm{Zn}$ among soil fractions. Soil samples were taken at the 0 to $20 \mathrm{~cm}$ depth from a long-term $(8 \mathrm{yr}$.) tillage experiment. The treatments were no tillage, minimum tillage (fall tillage only) and conventional tillage (spring and fall tillage). Soil samples were fractionated sequentially to determine $\mathrm{Mn}, \mathrm{Cu}, \mathrm{Fe}$ and $\mathrm{Zn}$ in the following fractions: exchangeable, organic, Mn-oxide, amorphous Fe-oxide, crystalline Fe-oxide and residual. Organic matter content and exchange capacity were higher in no-tillage treatment than in other tillage treatment. Tillage had more effect on the distribution of $\mathrm{Mn}$ and among fractions than on the distribution of $\mathrm{Zn}$ and $\mathrm{Cu}$. Mandal et al. (1990) found that the effect of different periods (0 and 15 days) of preflooding on the transformation of applied zinc in four lateric rice growing soils into its different forms namely (1) water soluble plus exchangeable (WSEX), organically complexed (OC), manganese oxide bound (MnOX), amorphous iron oxide bound (AFeOX) and crystalline oxide bound (CFeOX). Results showed that the transformation of applied zinc into WS, EX, OC, AFeOX and $\mathrm{CFeOX}$ forms were less, when zinc was applied after keeping soils preflooded for 15 days as compared to such transformation when zinc was applied immediately after flooding or pre-flooding. Prasad et al. (1995) observed that the transformation and availability of applied zinc in Calcareous soil treated with zinc sulphate and zinc fulvate (Zn-Fa). The application of varying levels of zinc through zinc fulvate augmented dry mater yield, zinc uptake and percent zinc derived from fertilizer more than that from zinc sulphate. The relative amount of zinc in various fractions and the relative distribution of applied 65Zn in these fractions at 25 days of maize growth were in order: CBD-extractable $\mathrm{Zn}>$ organically bound $\mathrm{Zn}>$ complexed $\mathrm{Zn}>$ water soluble>exchangeable $\mathrm{Zn}>\mathrm{HCL}$ soluble $\mathrm{Zn}$. The different fractions of zinc were increased with increasing levels of zinc. The path coefficient were step down regression analysis show that complexed $\mathrm{Zn}$ is the major source of zinc availability in calcareous soils treated with Zn-Fa and HCL extractable Zn and CBD-extrable Zn are important in soil treated with $\mathrm{ZnSO}_{4}$. Simultaneously the availability of $\mathrm{Zn}$ from all chemical pools in soils, directly and indirectly has been decreased through strong bonding with stable organic complexes. 


\section{MATERIALS AND METHODS}

The experiment was carried out in the Analytical Laboratory, Division of Soil Science under Bangladesh Agricultural Research Institute, Gazipur to find out the easily exchangeable Zn under aerobic and anaerobic conditions in Grey Terrace Soils, Non Calcarious floodplain Soils and Calcarious Floodplain Soils. On the basis of initial chemical analyses, incubation studies were carried out in 10 soil series representing important agricultural soils of the agro-ecological zones of Bangladesh to provide wide ranges of chemical and physical characteristics of the soils. The samples were collected from the surface layer $(0-15 \mathrm{~cm})$. After collection they were air dried, crushed and finally screened through a $2 \mathrm{~mm}$ sieve. There were 4 treatments consisting of 4 levels of $\mathrm{Zn}$ (3, 6, 9 and $12 \mathrm{~kg} \mathrm{Zn/ha)} \mathrm{from} \mathrm{zinc} \mathrm{sulphate} \mathrm{imposed} \mathrm{on} 6$ different soils and incubated both under aerobic and anaerobic condition up to 90 days. The experiment had three fold replication for each treatment and laid out in Completely Randomized Design. Measurement for different fraction of soil zinc were done at 4 periods as 15, 30, 6 and 90 days after incubation (DAI) both under aerobic and anaerobic condition. $30 \mathrm{~g}$ of air-dried $2 \mathrm{~mm}$ sieved soil sample was weighed into a incubated bottle (125 ml). The different amount of $\mathrm{ZnSO}_{4}$ for different treatments as a source of $\mathrm{Zn}$ was added and mixed thoroughly by small glass rod after adding water. The incubated bottles were covered with Para film and $4 \mathrm{~cm}$ standing water was maintained for anaerobic condition of the soils. To maintain aerobic condition in the incubated bottle, water was added as per requirement of the filled capacity for respective soil series. The soils were incubated at about $25^{\circ} \mathrm{C}$, being maintained for 15, 30, 60 and 90 days both for anaerobic and aerobic condition. After completion of incubation period the soil samples were allowed to air dry followed by crushing and passing through $2 \mathrm{~mm}$ sieve. Samples of each incubated soils were analyzed for exchangeable zinc, organic matter bond, manganese oxide bond, amorphous iron oxide bond, crystalline iron oxide bond zinc. $10 \mathrm{~g}$ of air dried $2 \mathrm{~mm}$ sieved soil and $40 \mathrm{ml}$ of $1 \mathrm{M} \mathrm{Mg}\left(\mathrm{NO}_{3}\right)_{2}$ were shaked for 2 hours in a $50 \mathrm{ml}$ centrifuge tube. The sample was centrifuged for 10 minutes, the supernatant decanted and $40 \mathrm{ml}$ of deionized water was added. The sample was then shaken for 30 minutes, centrifuged as before and the two centrifugates were combined for analysis ( Shuman, 1983).

\section{RESULTS AND DISCUSSIONS}

\section{Fractionation of Soil Zinc}

Sequential extraction procedures used to separate chemical forms of elements, especially metals, are being employed in the study of soils and sediments. These techniques are useful to the environmentalists, who use them primarily in research dealing with sewage sludge or sediments. Metal research is approached with the viewpoint of fertilizers to correct deficiencies and of elimination or inactivation of amounts toxic to plants. Fractionation schemes have not been standardized and each researcher uses his own scheme or a modification of one developed by another. However, the main interest of Zn fraction study was to document how the zinc applied to different soils was distributed in to various fractions when the soils incubated both under aerobic and anaerobic condition and to know the trend of changes at different interval of measurements up to 90 days. 


\section{Grey Terrace Soil under aerobic condition \\ Exchangeable Zinc}

Significant variation in exchangeable $\mathrm{Zn}$ was observed among the treatments at all intervals of incubation study. The highest exchangeable Zn (59 $\mu \mathrm{g}$ ml-1) was recorded in $\mathrm{T}_{4}$ at 15 days after incubation (DAI), which was identical with $\mathrm{T} 3$ but significantly higher over both $\mathrm{T}_{1}$ and $\mathrm{T}_{2}$ (Fig. 1). This fraction of soil Zn was sharply fell down at 30 DAI and showed more or less similar/static results up to 90 DAI. However, significant difference among the treatments was observed at all the periods of study. The variation among the treatments was also shown similar trends.

\section{Grey Terrace Soil under anaerobic condition Exchangeable Zn}

The trend of exchangeable-Zn was found similar to aerobic condition although anaerobic incubation provided lower results than aerobic condition. Significant and sharper differences were observed among the treatments at all the four periods of measurements (Fig. 2). The data varied from $8 \mu \mathrm{g} \mathrm{ml}-1$ to $55 \mu \mathrm{g} \mathrm{ml-1}$ where the highest value was observed in $\mathrm{T}_{4}$ at $15 \mathrm{DAI}$ and the lowest in $\mathrm{T}_{1}$ at $90 \mathrm{DAI}$. The first study at 15 DAI produced the highest result, which sharply fell down at $30 \mathrm{DAI}$ and then gradually but narrowly decreased up to 90 DAI. These results indicated that added Zn played very significant role to the exchangeable $\mathrm{Zn}$ fraction of soil and it tarnishes due to longer period of incubation. Pavanasasivam and Axley (1980) reported that flooding always causes a reduction in the Zn availability.

\section{Non Calcareous Grey Floodplain Soil under aerobic condition}

\section{Exchangeable Zn}

Different treatments showed significant variation in exchangeable Zn fraction at all four periods of measurements (Fig. 1). Treatment, T4 where higher amount (12.0 kg/ha) of Zn was added contributed significantly higher results than the rest of the treatments and this fraction of Zn gradually increased with the increase of added $\mathrm{Zn}$ which indicate that exchangeable $\mathrm{Zn}$ showed positively linear relationship with added Zn. However, the higher results obtained at 15 DAI and it sharply fell down at $30 \mathrm{DAI}$ and remained more or les static up to 90 DAI. These results indicate that the exchangeable fraction of soil $\mathrm{Zn}$ remain more or less static when the equilibrium condition in soil solution was achieved. However, difference due to various treatments was seen even after longer period of incubation.

\section{Non Calcareous Grey Floodplain Soil under anaerobic condition}

\section{Exchangeable-Zn}

Added zinc showed highly significant contribution to the exchangeable $\mathrm{Zn}$ even under anaerobic condition at every period of study (Fig.2). The effect due to $\mathrm{T}_{4}$ was very prominent than rest of the treatments irrespective to the periods of measurements. The result was found higher at 15 DAI but remaining three measurements showed more or less similar results. Although the trend of exchangeable-Zn was found similar both at aerobic and anaerobic condition but the results obtained in later were many folds lower than the former. These results indicate that anaerobic condition depressed 
the exchangeable zinc content of the soil even if the treatments and other condition of the measurement remained alike.

\section{Calcareous Dark Grey Floodplain and Brown Floodplain Soil under aerobic condition Exchangeable Zn}

Different treatments produced significantly higher amount of exchangeable Zn under aerobic condition irrespective to the different periods of incubation study (Fig.1). The results obtained with $\mathrm{T}_{3}$ and $\mathrm{T}_{4}$ at 15 DAI was several folds higher than those derived in 30, 60 and 90 DAI. At 15 DAI, the amount of exchangeable $\mathrm{Zn}$ reached at the peak (30 $\mu \mathrm{g} \mathrm{ml}-1$ ) for $\mathrm{T}$, which sharply fell down to $11 \mu \mathrm{g} \mathrm{ml}-1$ at 30 DAI and further decreased to $7 \mu \mathrm{g}$ ml-1 at 90 DAI for the same treatment. The other treatment also showed the similar trends but the effect was sharper as in the order of $\mathrm{T}_{4}>\mathrm{T}_{3}>\mathrm{T}_{2}>\mathrm{T}_{1}$. These results also revealed that the amount of exchangeable $\mathrm{Zn}$ decreased as the incubation periods proceed to longer duration where the equilibrium condition attained.

\section{Calcareous Dark Grey Floodplain and Brown Floodplain Soil under anaerobic condition Exchangeable Zn}

Exchangeable-Zn fraction showed almost similar results and pattern of distribution as was seen in case of aerobic condition. This result revealed that anaerobic condition did not alter the exchangeable fraction of zinc as was found in aerobic condition. However, the treatment effect was found significant and very distinct from each other irrespective to periods of measurements (Fig.2).
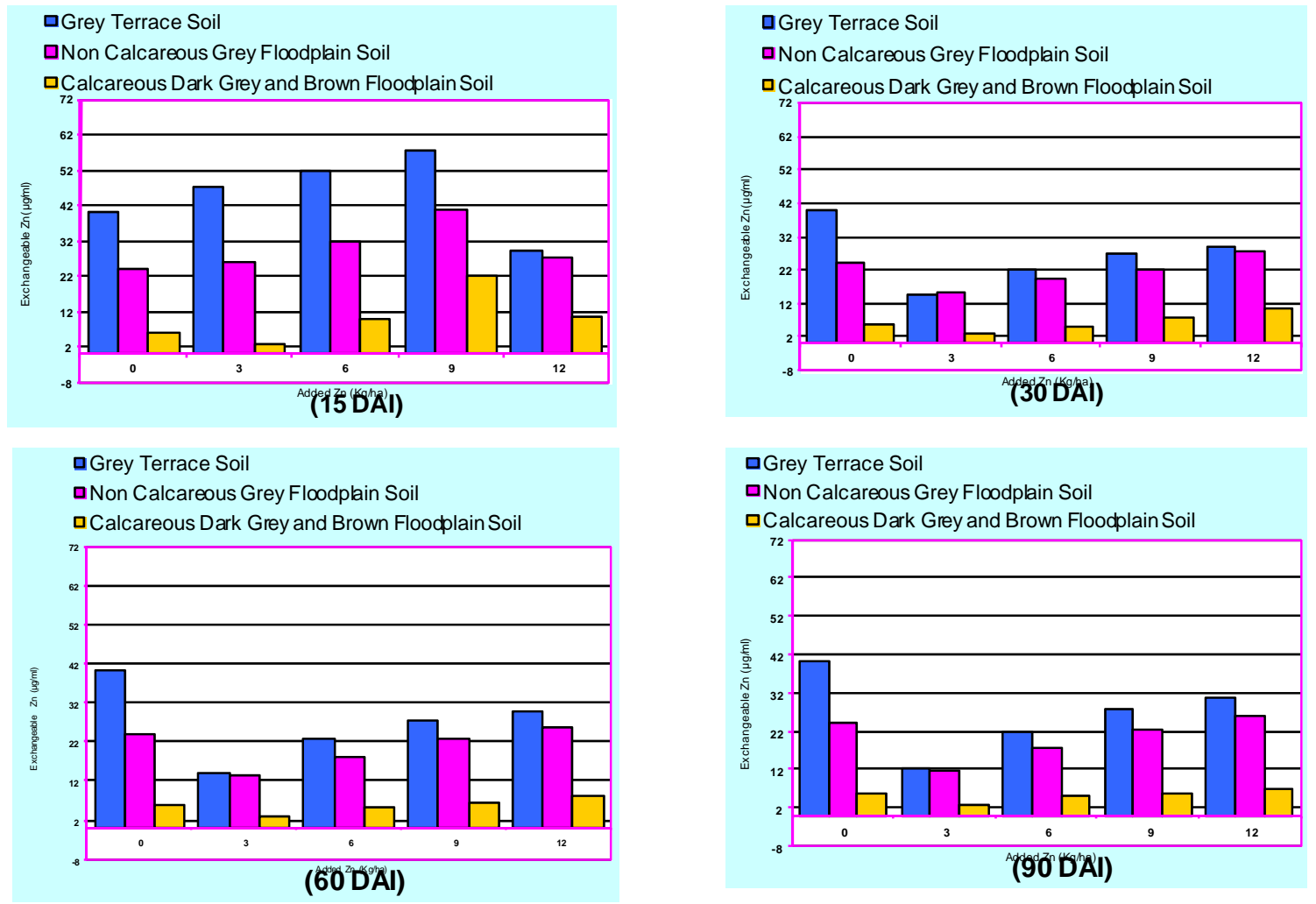

Fig-1: Exchangeble Zn for varying levels of added Zn in 3 types of soils under aerobic conditions at 15, 30, 60, and 90 DAI. 

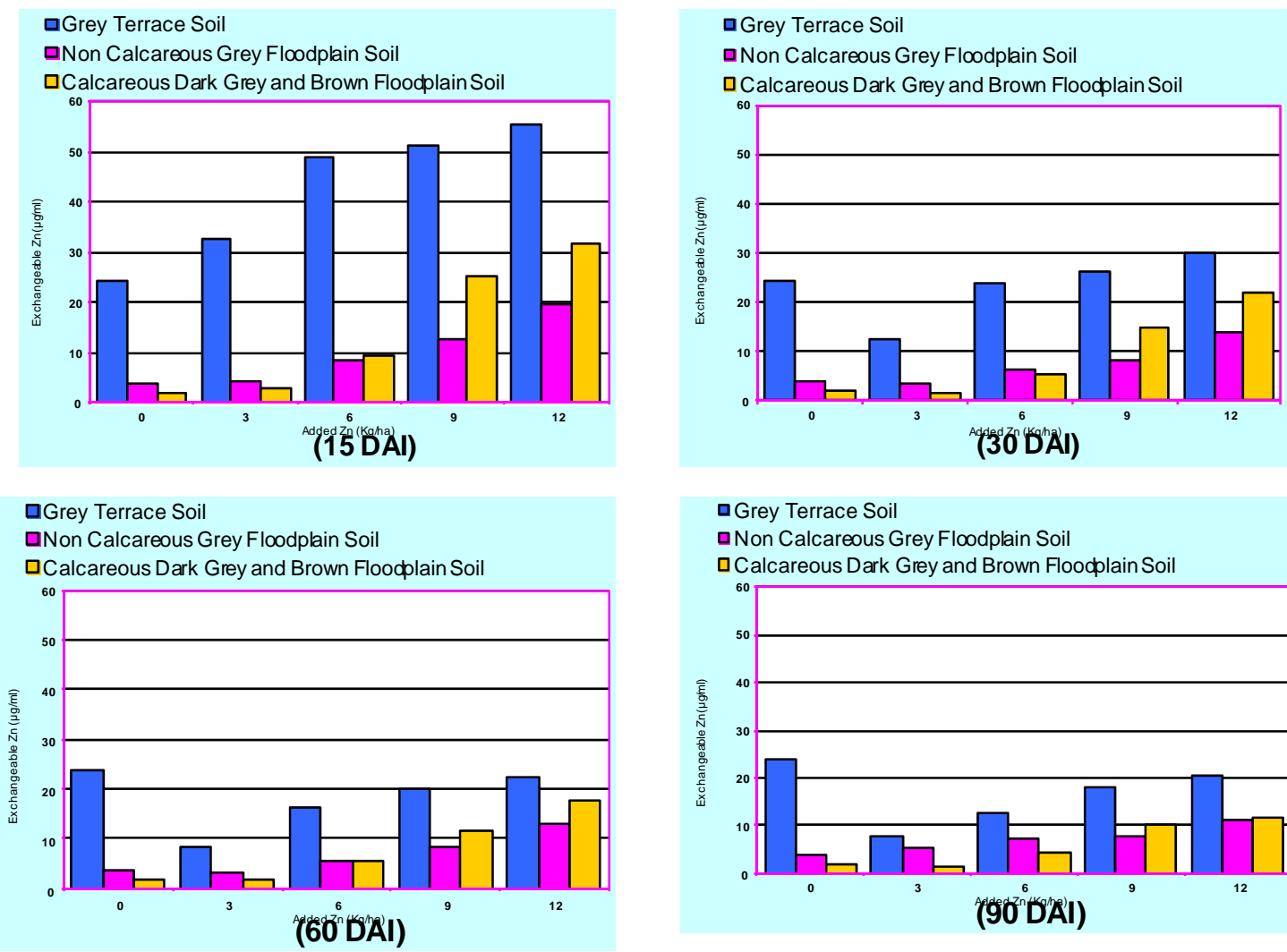

口Grey Terrace Soil

口Non Calcareous Grey Floodplain Soil

口Calcareous Dark Grey and Brown Floodplain Soil

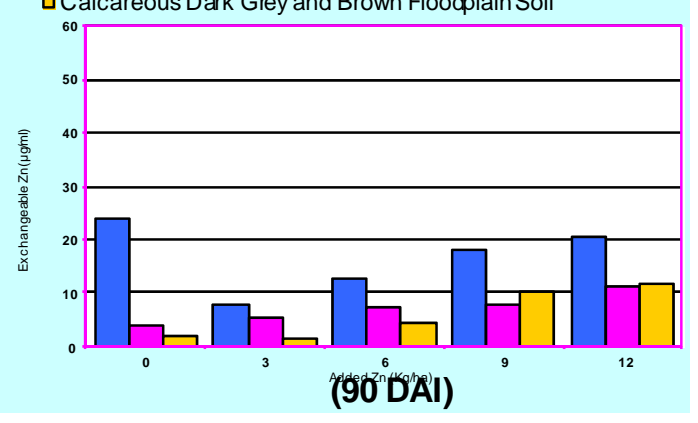

Fig-2: Exchangeble Zn for varying levels of added Zn in 3 types of soils under anaerobic conditions at 15, 30, 60, and 90 DAI.

\section{REFERENCES}

Iyengar, S. S.; Martens, D. C. and Miller, W. P. 1981. Distribution and plant availability of soil zinc fractions. Soil Sci. Sco. Am. J. 45: 735-739.

Mandal, B.; Chatterjee, J.; Hazra, G. C. and Mandal, L. N. 1990. Effect of preflooding on transformation of applied zinc and its uptake by rice in lateritic soils. Soil Sci. 153: 250.

Pavanasasivam, V. and Axley, J. H. 1980. Effect of sulphur and potassium on zinc absorption by barley. Plant Soil 64: 393-401.

Prasad, B.; Mehta, A. K. and Sinha, M. K. 1980. Zinc fractions and availability of applied zinc in calcareous soils treated with organic material. J. Ind. Soc. Soil Sci. 38: 248-253.

Prasad, B.; Sarangthem, I. and Chowdhary, K. C. 1995. Transformation and availability at applied zinc to maize in calcareous soil. Indian Soc. of soil Sci. 43: 84-89.

Prasad, R. and Sakal, R. 1988. Effect of soil properties on different chemical pools of zinc in calcareous soils. J. Ind. Soil Sci. 36: 246-251.

Shuman, L. M. 1983. Zinc in soils. In. Zinc in the Environment edited bly Nriagu, J. O. Wiley NY. Part I. 40-69 pp.

Shuman, L. M. 1985. Fractionation method for soil microelement. Soil Sci. 140: 11-12. 